\title{
9 \\ National Data: Reflecting Northern Australian Aspirations?
}

\author{
Don Zoellner and Judith Lovell
}

\section{Introduction}

This chapter reports on the continued exploration of the capacity of existing data sources to describe the economies of three groups of remote Aboriginal settlements in the Northern Territory (NT). The purpose is to contribute research that supports better place-based policy fit with remote settlements to augment opportunities for social and economic benefit. Understanding how the non-market (governments, philanthropic foundations and/or charities) might better amplify local, open and competitive market capacities requires rethinking fundamental constraints applied to the interpretation of national data. This includes an acceptance that remoteness has many facets and remains difficult to describe using existing economic and population data sets.

Building on an earlier analysis of the ways socioeconomic aspirations are manifested, each of the 15 settlements described below continued their assignment to one of three clusters. This was based on three types of economic activity, each of which was derived from combining various levels of mixed-market activity (Lovell et al., 2015a). Mixed-markets incorporate competitive market activity with non-market interventions taking into account customary socioeconomic practices. The original interrogation of the 2011 national census data, when combined with 
industry knowledge, confirmed that mixed-market economies are operating in remote and very remote Aboriginal settlements, but their activity is likely to be underestimated.

The analysis reported in this chapter examines and then dismisses longitudinal national data sources and returns to Australian Bureau of Statistics (ABS) categories of employment and income data to determine if a more comprehensive view of the mixed markets can be obtained and used to develop fit-for-purpose public policy responses. The field of this research is at the complex intersection of employment, occupation, labour force, taxation, social welfare and socioeconomic activity in remote communities, which are sparsely populated and whose residents are highly mobile—between settlements and beyond.

The work reported here extends the original analysis of three clusters of remote Aboriginal settlements in the NT, their economic capacity/ advantage and the existence of mixed-market economies. The locations of these communities are shown in Figure 9.1. The previous research used a snapshot of national ABS census data from 2011 and available industry information to hypothesise that mixed-market economic activity is under-reported in these communities (Lovell et al., 2015a). In addition, these Australian clusters were compared to remote Canadian Indigenous communities, finding that similar issues are apparent in both countries regarding the limits to data adequacy, resulting in constraints on the understanding of economic activity and the development of public policy (Lovell et al., 2016).

There are vulnerabilities in analysis of sparsely populated settlements in remote regions and constraints in the data that present a methodological challenge to formal and social demographers (Carson et al., 2015). While the statistical limitations inherent in small sample sizes extracted from large data collections are well known, the ABS census data appears to be the best option available. The whole of population data has proven to be only marginally useful when attempting to understand, and exert policy influence on, the behaviour of individuals in the two advanced market democracies of Australia and Canada (Lovell et al., 2016; Pearson \& Daff, 2014; Sengupta et al., 2015). 


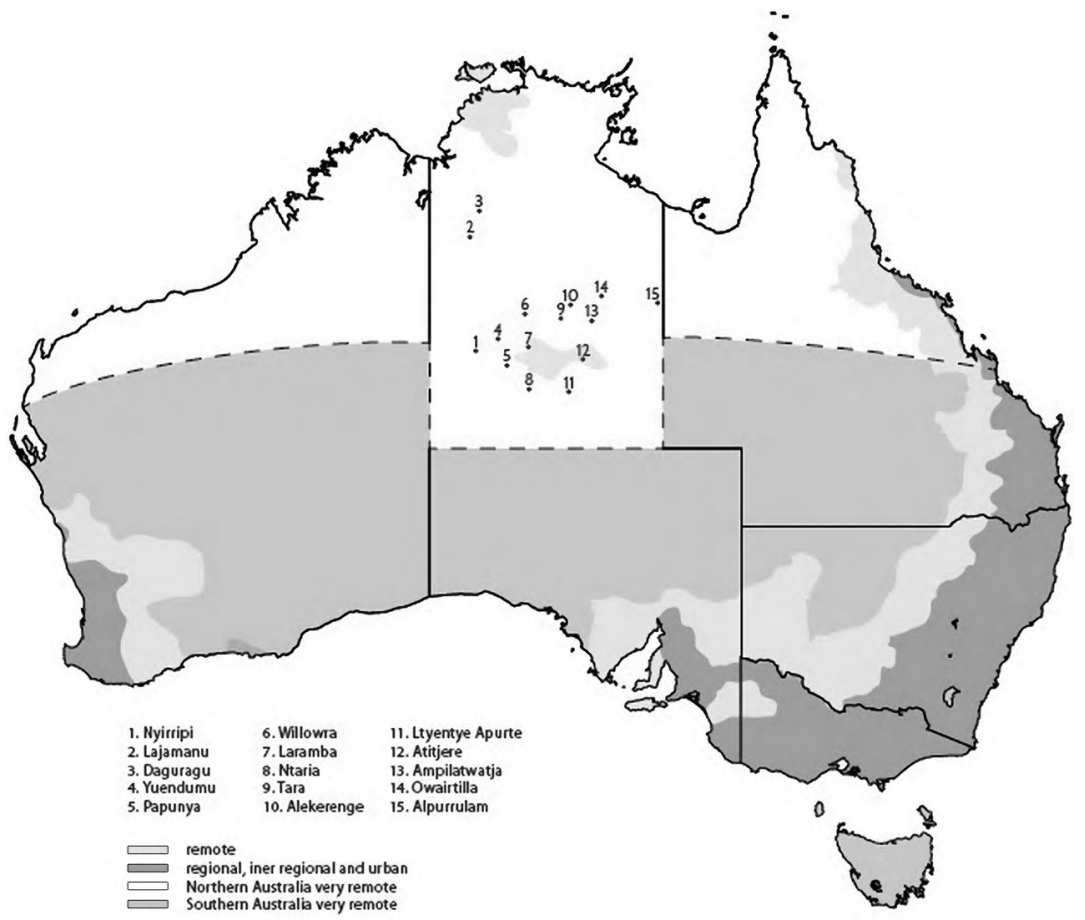

Figure 9.1: Map of remote and very remote Australia indicating the locations of settlements included in Clusters One, Two and Three.

Source: Ninti One Ltd (cartographer) and J. Lovell.

\section{Contextual Considerations}

As non-Indigenous researchers writing about Aboriginal settlements, we acknowledge a configuration in which Aboriginal sovereignty and standpoints are part of the lived experience that Aboriginal residents of remote settlements bring to an interface with other ideological structures and standpoints (Morrison, 2015; Nakata, 2007). We do not claim to represent Aboriginal or Torres Strait Islander standpoints. It is the national construction of remoteness that provides the context for the arguments presented below on the basis of decades of working at the contemporary intercultural interface. It is the shortcomings of national data being used to develop policies that are the focus of this chapter and we acknowledge that the residents in these communities will have alternative perspectives. 


\section{The Construct of the Clusters}

The three clusters of Central Australian settlements under examination are not geographically contiguous, as opposed to the standard categories for the national census data collections. The 15 communities have been grouped on the basis of employment in three, one/two or none of the activities that can be reliably described by industry knowledge over time. These include ranger groups, art centres and Aboriginal community researchers (Lovell et al., 2015b, p. 4). Given the constraints of the data used to construct these novel assemblages and to seek further support for the hypothesised under-reporting of mixed-market activity and its economic contribution in these communities, the search for additional sources of information was undertaken. What follows are the results of that exploration.

\section{HILDA}

The Household, Income and Labour Dynamics in Australia (HILDA) survey is conducted annually using a nationally representative sample to inform a longitudinal study that began with the first wave in 2001 (Wilkins, 2015, p. 4). Results are used to report national trends on a range of matters including those potentially relevant to the analysis of the mixed markets of very remote Australian communities. Specific items include income, expenditure, employment, education and attitudes and values on an array of subjects. Wave One contained 7,862 households occupied by 19,914 residents, of which only those aged 15 years and over were interviewed (Wilkins, 2015, p. 93).

The original design of the representative sample for HILDA's Wave One excluded five groups from consideration, including those who were in the defence forces, overseas residents, those institutionalised (e.g. in prison or hospitals) or 'people living in remote and sparsely populated areas' (Watson $\&$ Wooden, 2002, p. 3). This decision was made on the basis that:

the focus of the HILDA [is] on producing nation-wide population estimates, [it is] our view that any benefits from a differential probability approach to sampling are outweighed by the negative impacts on overall statistical efficiency. (Watson \& Wooden, 2002, p. 6) 
As a result, the vast majority of the NT landmass was excluded from the national population reference sample, although the two larger towns nearest the clusters, Alice Springs and Tennant Creek, were included. This initial design decision to exclude very remote communities remains a feature of the newest waves studied through HILDA because the residents are not considered to be 'in-scope' (Wilkins, 2015, p. 93).

\section{LSAY}

A second long-running longitudinal survey of young people has its roots in the 1970s and is currently known as the Longitudinal Surveys of Australian Youth (LSAY). It also relies on a nationally representative sample of Year 9 students chosen every third year since 1995 and each cohort has been 'topped up' to retain statistically relevant numbers (Jones, 2002 , p. 1). In more recent times, the construction of the sample selection has also been aligned with the results of international testing schemes of reading, writing and mathematics conducted in Australian schools. Since 2003, about 14,000 students are recruited into the new cohort drawn from 350 schools in all states and territories (National Centre for Vocational Education Research, 2014, p. 18). The survey also collects information that would be relevant to the study of remote mixed markets, such as levels of education and training, work and social development; however, the word remote is not used in favour of a binary distinctionmetropolitan or non-metropolitan (National Centre for Vocational Education Research, 2014, p. 18).

It is reported that one of the earlier studies in this series, the 1989 Australian Youth Survey, drew its sample 'from a list of ABS collection districts from non-remote areas' (Australian Council for Educational Research, 1997, p. 6). This survey gathered information on education and training pathways leading to engagement with the labour market from 5,350 16-19-year-olds and, again, new 16-year-olds were added in each year to maintain statistical validity (Australian Council for Educational Research, 1997, p. 2). By the mid-1990s, LSAY had incorporated the ABS measure of remoteness in preparing the selected sample of some 13,000 Year 9 students that would be tracked to post-school study and employment (Jones, 2002, p. 1). Because there were only 365 remote Indigenous students in the sample, Jones (2002, p. vii) proposed that in light of these sample distribution problems, the use of LSAY data for national reporting of outcomes by geographical location is not recommended'. 


\section{SEIFA}

The Socio-Economic Indexes for Areas (SEIFA) ranks areas in Australia according to 'relative socio-economic advantage and disadvantage' (ABS, 2013b, p. 1). The tool was initially produced with five indexes, of which one contained a rural measure, but none that are remote or very remote. In 2006, this was conflated into four indexes, again without remote or very remote scalable indices. These focus on various aspects of socioeconomic advantage and disadvantage in the form of a summary of subsets of census variables that assist in defining how access to material and social resources is related to the ability to participate in society. According to the ABS, 'the common uses of SEIFA include:

- determining areas that require funding and services

- identifying new business opportunities

- assisting research into the relationship between socio-economic disadvantage

- and various social outcomes' (p. 1).

With each census SEIFA updates its measures and in 2011 ceased using Indigenous/non-Indigenous status as a variable on the basis that there was an increase of 21 per cent of the population who indicated Indigenous status in 2011, which was recorded mainly in urban areas. In the past, Indigenous status has been used as a proxy for disadvantage in SEIFA, but this is no longer the case. The index is not designed for longitudinal or time series analysis - it is a snapshot of place and time. SEIFA reflects the collective characteristics of an area, settlement or neighbourhood and not the individual variances between residents.

The Index of Relative Socio-Economic Disadvantage (IRSD) ranks residents into levels of disadvantage, aggregated at settlement (or neighbourhood) level. There is less ranking of advantage in the IRSD than in the Index of Relative Socio-Economic Advantage and Disadvantage (IRSAD). IRSAD aggregates both advantage and disadvantage and the difference from one to the other is offset by the impact on the area from having advantaged residents. The Index of Economic Resources (IER) is based on area-level income data and assumes that 'areas with higher scores have relatively greater access to economic resources than areas with lower scores' (ABS, 2013b, p. 8). In 2011, the index discounted any income below $A \$ 1$ per week. The Index of Education and Occupation (IEO) 
focuses on the skills and qualifications required to perform different occupations and aggregates the numbers of people with or without qualifications, with or without jobs and in high- or low-skilled jobs.

SEIFA has a process of exclusion for geographical areas in which census data cannot provide information for enough variables in some or all of the indices. This is where the index parts ways with national perspectives of remote and very remote settlement-level data as the data cubes available are already constrained to comparatives within a state or territory. On the basis of the 2011 exclusion rules, 2,231 Statistical Area 1 level blocks (SA1) were excluded and from a total of 54,805 areas (ABS, 2013b, p. 28). In the NT, the socioeconomic indexes for SA1 areas in 2011 returned summary data for 14 of the 15 settlements analysed. Unsurprisingly, the IRSAD, IRSD and IER scores across the clusters are all in the decile 1-that is, in the lowest 10 per cent of SA1 areas when compared within all NT SA1s.

The glaring exception to our clusters dominating the lowest deciles is in the IEO, which indicates a number of residents in the middle ranges in some settlements. Due to the fact that SEIFA no longer distinguishes Indigenous status, it is likely that these higher deciles reflect non-Indigenous/ not-stated workers in schools, health clinics, business manager positions or other government positions. The deciles for IEO range from 1 (lowest 10 per cent) up to 4 (lowest 40 per cent) in the different communities.

\section{Constraints}

With the total exclusion of remote residents in HILDA and the dubious nature of the sample base in LSAY, neither of these potentially useful longitudinal surveys can contribute to our basic understanding of remote mixed-market economies. The long-term nature of these surveys not only provides stable information from the same (or similar) persons but allows for trends to be observed and causal relationships to be surmised. For example, HILDA suggests that credible causal relationships can be inferred about the effects of various factors on life outcomes such as earnings, unemployment, income and life satisfaction' (Wilkins, 2015, p. 4). Similarly, LSAY proposes that the data it gathers allows for 'quasiexperimental' research designs (National Centre for Vocational Education Research, 2014, p. 10). This is because before-and-after information for interventions, such as gaining a qualification, can be analysed for effect 
(e.g. employment), providing some indications of causality, although readers are warned 'causality is never really established in the social sciences' (National Centre for Vocational Education Research, 2014, p. 10).

The integrity of these longitudinal studies relies on consistency and it seems unlikely that important features in the economic and social lives of the population who live in remote communities will be added to the samples, thus making it impossible to extract the same type of information that is readily available for urban and regional areas. This is problematic in public policy making because 'longitudinal data are very important to governments in the development of policy as they provide robust evidence to inform policy and debate' (National Centre for Vocational Education Research, 2014, p. 10). Those who contribute to policy debates on responses to remote Indigenous disadvantage, such as 'closing the gap' (Austin-Broos, 2011; Australian Government, 2015a) and the Indigenous Advancement Strategy (Department of the Prime Minister and Cabinet, 2014), do not have access to the same level of credible information and inferred causality as is used in making decisions for the vast majority of the population that have been included in the national longitudinal samples.

It is important to reiterate that differences shown in the derived data in the tables that follow must be understood as being snapshots of two points in time, unlike the longitudinal trend characteristics that can be described from HILDA and LSAY surveys. Comparisons are highly speculative and suggestions of causality cannot be supported from these point-in-time data. Nevertheless, this is the best statistical base available. There was an overall decline of 2 per cent in the Indigenous population of remote and very remote areas of Northern Australia (see Figure 9.1) between the census collection points of 2006 and 2011, with migration into regional and urban centres (Taylor et al., 2015).The combined Aboriginal population of the southern region of the NT is approximately 17,500 people including those normally resident in the three clusters of communities (Central Land Council, 2015a). Approximately 5,500 Aboriginal people were usually resident in the 15 settlements in these clusters, according to the 2011 census (ABS, 2014). 


\section{Method}

In this analysis, a census snapshot from 2006 is compared with the 2011 data and relevant industry information where it is available. With the addition of 2006 data, the presence or absence of mixed-market activity can be seen to have changed between the two census collection points. There is a slight change to the settlements with the inclusion of Tara in Cluster Three and Atitjere in Cluster Two in 2011, which is not evident in our search using TableBuilder Pro Census 2006 data (ABS, 2014). Otherwise, the groupings of communities, on the basis of known economic activity and industry knowledge, remains the same as in the previous research that used 2011 data (Lovell et al., 2015b, p. 4).

Using selected characteristics of labour force and population, employers and employees, and income and employment, this analysis provides the two snapshot points from ABS (2014) census data against which the magnitude of market and non-market activity can be considered, based on the presence or absence of the three mixed-market activities: art centres, ranger groups and Aboriginal community researchers. The clusters used here consist of the following communities:

- Cluster One includes Ntaria and Tjuwanpa, Lajamanu, Ltyentye Apurte (Santa Teresa), Yuendumu and outstations and Papunya and its outstations:

- three settlements had an active art centre in 2006, and five in 2011

- three settlements had an active ranger program in 2006, and five in 2011.

- Cluster Two includes Atitjere, Darguragu-Kalkarintji, Owairtilla (Canteen Creek), Ampilatwatja and Alekerenge (Ali Curung):

- zero art centres in 2006 and two in 2011

- one ranger group starting up in 2006 and three in 2011.

- Cluster Three includes Wirliyatjarrayi (Willowra), Alpurrurulam, Nyirripi, Laramba and Tara (which became a gazetted area in 2011 and, therefore, did not contribute to the 2006 data):

- zero active art centres at either point

- no formal ranger program at either point although one community has rangers locally based but employed through another community's program. 


\section{Interpreting the Data}

The 2006 and 2011 ABS census points are compared by using the following standard classifications (ABS, 2013a):

- Population, Occupation (OCCP)

- Labour Force (LFSP) statistics for Indigenous (INDG) and Non-Indigenous or Not-Stated (NI-NS) status

- Place of Usual Residence (POUR)

- Income (INCP)

- Employment (EMTP)

- Government/Non-Government Employment Indicator (GNGP).

The settlement data used throughout for comparison into Clusters One, Two and Three have been aggregated using the ABS TableBuilder Pro software (ABS, 2014) unless otherwise stated.

For the purpose of the Australian Census, participants in the labour force must be aged 15 years or older and employed at least one hour per week. The income data is calculated on the previous week and may not translate to annual amounts. The unemployed must be actively seeking work, be 15 years or older and not working more than one hour per week. The labour force in each settlement is a combination of those who are employed along with those who are officially unemployed.

Occupational data were found to be an inaccurate reflection of the mixed-market activities occurring in the industries selected. Some operate informally and without the correlation of financial income to product or service provided and residents often have more than one form of occupation, whereas the census question allows for a single response only (Lovell et al., 2015a). Economic participation is understood to be sporadic in remote and sparsely populated settlements, where variables include seasonal conditions, cultural obligations, shifts in policy and programs and movement of local residents in and out of communities (Carson \& Carson, 2014; Dockery, 2014a, 2014b). In addition, migratory professional workforces account for high levels of mobility among nonlocal staff such as school and health staff, service managers and government business officers (Carson \& Carson, 2014; Haslam McKenzie, 2011). 
In 2006, the ABS added a series of questions relating to employment type, which 'classifies all employed people to either employees, ownermanagers of incorporated enterprises, owner-managers of unincorporated enterprises or contributing family workers, on the basis of their main job' (ABS, 2012a). In the 2011 census, the Public/Private Employer Indicator classifies people 'as to whether their employment was in the government (public) or non-government (private) sector. The public sector is further broken down into National, State and Territory or Local Government' (ABS, 2012b). Both of these classifications discount persons who are under 15 years, unemployed, outside the labour force or whose status is not stated as within the labour force.

Using the two census collection points and the characteristics of employees and employers in the three clusters, two snapshots of the magnitude of market and non-market activity can be speculated on. As theorised by Wolf (1993, pp. 37-38), markets are characterised by free choice and strong price signals in which participants are protected by the minimum amount of regulation required to promote fair trading conditions resulting in efficiency and some measure of distributional equity of resources. The non-market alternatives generally include government-delivered programs, charitable efforts or philanthropic endeavours. Among the clusters in this study, non-market alternatives are more prevalent, but, as the data confirms, they do not necessarily produce equitable outcomes. Non-market failure often contributes to unintended consequences, disjunctions and tipping points that affect remote residents and settlements in ways contrary to the original intentions (Carson \& Carson, 2014). Non-market failures are also reflected in the vision and management of remote environments (Woinsarski et al., 2014).

\section{Employers and Employees}

Before examining the data for types of employment, several limitations concerning what is represented need to be stated. First, it is unlikely that philanthropic organisations will self-identify as a member of the nonmarket group, although Wolf (1993) theorised their activities as other than being active in the marketplace. In some cases, not-for-profit companies also contributed to the opportunity structures of the mixed-market sample described in the previous research brief (Lovell et al., 2015b). Second, it is equally unlikely that an employee of the Central Land Council will 
self-identify as working for the Australian Government, although the NT land councils are statutory authorities of the national government (Central Land Council, 2015a).

The choices of answers for the census question for government or private sector employment include one of the three levels of government or private sector (GNGP). Further choice for answering the question includes 'not stated' or 'not applicable'. When read in addition to the results for employment type, almost all respondents describe themselves in a government or private sector employment and as 'employees not owning a business' (EMPT). These classifications are aggregated in the figures below, for each cluster by using the GNGP and EMPT.

Using Wolf's (1993) criteria of market and non-market it is clear that employment data in these clusters suggests an almost exclusively nonmarket economy, despite the GNGP classifications as 'government' or 'private sector'. This is further supported through the EMPT data in which almost all employees report working for businesses they do not own. There appears to be close to zero open and competitive 'market' activity prompting the observation that the outsourcing of public services from government to other providers has not created market activity in the clusters. Crucially, this census data does not disclose that the nature of so-called 'private sector' employment is essentially non-market because industry knowledge indicates the ultimate source of revenue comes from taxes or other non-priced sources in most cases. For example, tracing back the source of funding for the ranger programs, a major form of 'private' employment, takes one to Australian Government 'Caring for Country' allocations to the Central Land Council (Central Land Council, 2015b). Likewise, this analysis does not describe fluctuations or changes in customary socioeconomic activities that are not captured by contemporary financial measures. However, it is recognised that such activities play an essential role in the wellbeing of residents throughout these settlements. 


\section{Data}

\section{Labour Force and Population}

Figure 9.2 provides a comparison between clusters and collection points in labour force and population. The Cluster One census reported an Aboriginal and Torres Strait Islander population of 2,891 and NI-NS population of 260 in 2006. In 2011, those figures were 2,668 and 349 respectively, which indicates a decline in Aboriginal population (-23) and an increase in non-Indigenous population $(+89)$ between collection points. The Indigenous labour force in 2006 was 606 and the NI-NS labour force was 180. In 2011, Indigenous labour force rose (+6) to 612 despite the decreased population, while the NI-NS labour force also increased $(+37)$ to 249 in line with the reported population increase.

The Cluster Two census recorded an Indigenous population of 1,292 and NI-NS population of 74 in 2006. In 2011, those figures were 1,889 and 205 respectively, which indicates an increase in Aboriginal populations $(+597)$ and an increase in NI-NS populations $(+131)$ between collection points. The increase in the Indigenous population is partly explained through the addition of one settlement to the cluster data in 2011 (+164 Indigenous residents). The Indigenous labour force in 2006 was 340 and the NI-NS labour force was 48. In 2011, the Indigenous labour force increased $(+6)$ to 346 and the NI-NS labour force increased $(+131)$ to 205 . The very slight increase in the Indigenous labour force $(+6)$ cannot be adequately explained in light of the +164 Indigenous residents at Atitjere being added to the cluster in 2011 data. The increase in NI-NS population attributed to the additional settlement was +21 , which contributes to the overall increase in NI-NS labour force in this cluster and also aligned to population increase.

The Cluster Three census showed an Indigenous population of 1,071 and NI-NS population of 172 in 2006. In 2011, those figures were 1,090 and 94 respectively, which indicates an increase in Aboriginal population (+19) and a decrease in NI-NS populations (-78) between collection points. The data for Cluster Three in 2011 also includes an added settlement with an Indigenous population of +53 and NI-NS population of +4 . The Indigenous labour force in 2006 was 180 and the NI-NS labour force was 119. In 2011, the Indigenous labour force was $212(+32)$ and NI-NS was $76(-42)$. Some of the increases across the cluster are attributed to the inclusions of the newly gazetted settlement between censuses. 


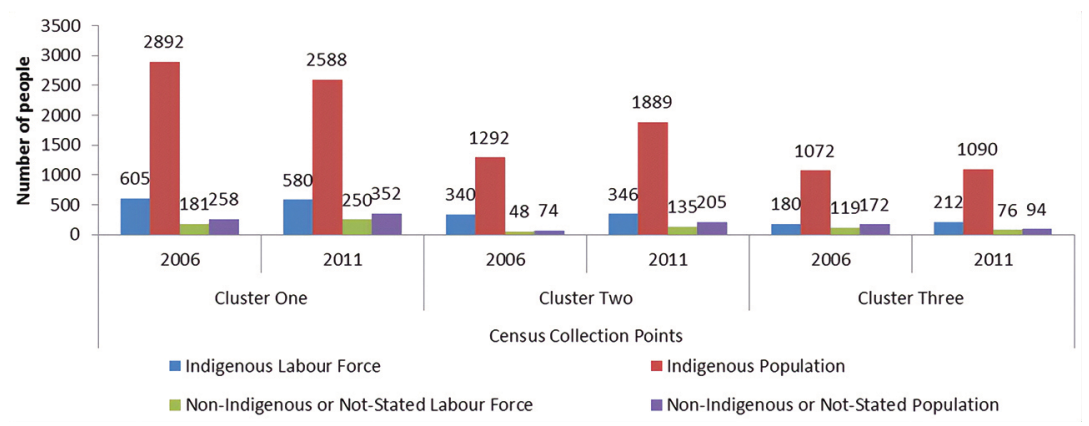

Figure 9.2: Indigenous and NI-NS labour force and population by clusters and census points.

Source: Authors' research.

Evidence of population mobility between census points is well documented (Carson et al., 2015; Dockery, 2014a; Taylor et al., 2015) and the population data above further supports findings of mobility. However, intra-settlement mobility does not fully explain the labour force changes across these settlements, which must be understood in relation to a national ideological shift in policy, which saw strong targeting of remote Indigenous employment across governments' policy agendas (Forrest, 2014; Limerick et al., 2014; Steering Committee for the Review of Government Service Provision, 2014). Cluster One labour force decreased 4.4 per cent and the population decreased 11.5 per cent. Cluster Two labour force increased 1.8 per cent whereas the population increased 32 per cent. Cluster Three labour force increased 16 per cent between collection points, whereas the population increased 1.7 per cent.

When comparing the absolute numbers of Indigenous people in the labour force, there are noticeable differences between the clusters. A stronger mixed market, larger population and higher levels of both Indigenous and non-Indigenous employment are present in Cluster One and are lowest in Cluster Three, which has been previously demonstrated to have minimal mixed-market activity. Of course, these observations cannot be interpreted as trends in each cluster nor can causality be determined. Nevertheless, it is not unexpected that larger population centres have more extensive social and physical infrastructure and may be more attractive places in which to invest in more complex mixed-market activities compared to smaller settlements. Clearly, this data also suggests that Indigenous population are not nearly as engaged in labour force activity as the nonIndigenous residents in each of the clusters. One reason for this is the 
migratory nature of non-Indigenous residents who travel and reside in a remote settlement on the basis of an employment contract, or as family members of those who relocate for employment.

\section{Government/Non-Government Employment Indices}

The next set of ABS data that might be used to distinguish between market and non-market activity in the clusters comes from employment responses at the two census points (see Figure 9.3). The following is stratified from within labour force and population demographics presented above, according to the three classifications of not-stated, private sector and the combined governments sector (e.g. local, territory and federal). Additionally, the figure for persons employed, but not owning a business is marked on each bar with ' $\mathrm{X}$ '.

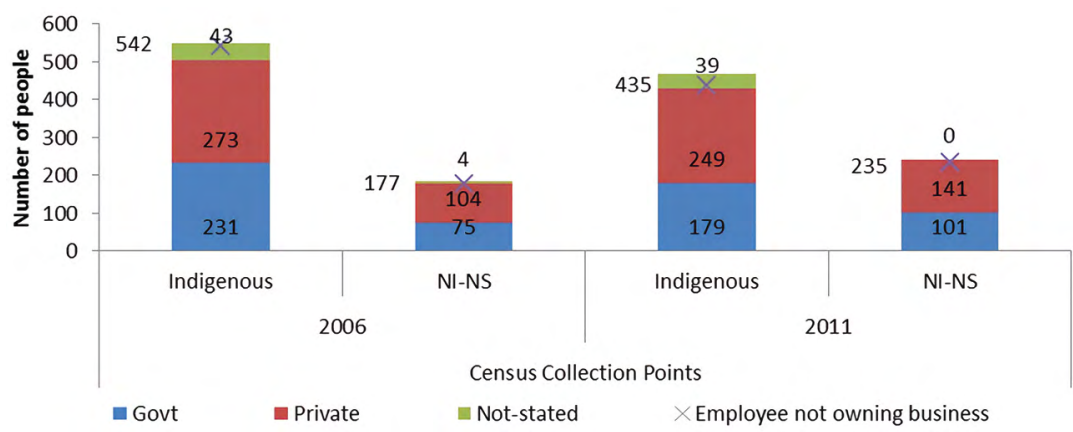

Figure 9.3: Cluster One showing combined government and private sector employment indices and employment type for 2006 and 2011, using the categories of Indigenous and NI-NS.

Source: Authors' research.

There are 547 Indigenous employees in Cluster One in 2006, of which 542 recorded they were employed in a business they did not own, while five nominated as owner-managers of unincorporated enterprises. In 2011, of a possible 467 Indigenous employees, 435 worked in a business they did not own and 32 worked as owner-managers of unincorporated enterprises. What the nature of those unincorporated enterprises was is not possible to define. These residents could be entrepreneurs producing goods or services for arts markets, undertaking fee-for-service for nonmarket agencies such as Land Councils or providing skills to not-for-profit or commercial employers in roles such as researchers and interpreters. 
The correlating findings for NI-NS status people shows 183 employees in 2006, of which six selected owner-manager of unincorporated enterprise and the remaining 177 were employed in a business they did not own. In 2011, of a possible 242 NI-NS employees, 235 worked in a business they did not own and seven worked as owner-managers of unincorporated enterprises. The increase in NI-NS employees occurred predominantly in territory government $(+32)$ and in those who indicated they held private sector employment $(+37)$.

In Figure 9.4, Cluster Two data includes 230 Indigenous employees in 2006 who were employed in a business they did not own and no ownermanagers of unincorporated enterprises. In 2011, of a possible 262 Indigenous employees, 258 worked in a business they did not own with four working as owner-managers of unincorporated enterprises. As in Cluster One, it is not possible to define these enterprises-they could be entrepreneurs producing goods and services or providing fee-for-service outputs to both market or non-market agents.

The correlating findings for NI-NS status people shows 66 employees in 2006, of which nine selected owner-manager of incorporated or unincorporated enterprise and the remaining 57 were employed in a business they did not own. In 2011, of a possible 184 NI-NS employees, 163 worked in a business they did not own and 21 worked as ownermanagers of incorporated or unincorporated enterprises. The increase in NI-NS employees occurred predominantly in territory government $(+38)$ and reported private sector employment $(+71)$.

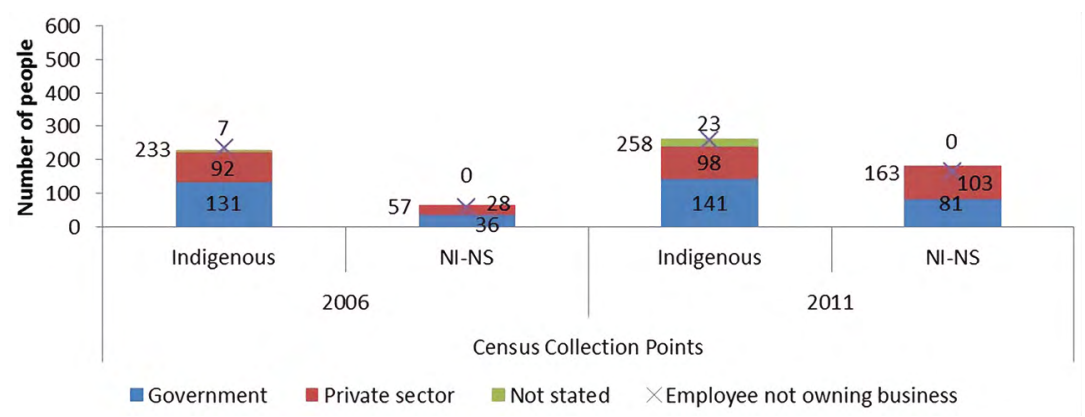

Figure 9.4: Cluster Two shows combined government and private sector employment indices and employment type for 2006 and 2011, using the categories of Indigenous and NI-NS.

Source: Authors' research. 


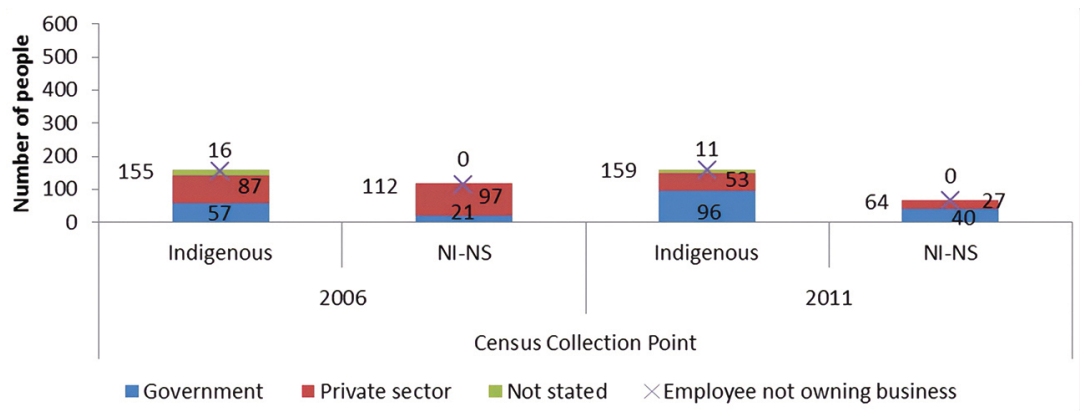

Figure 9.5: Cluster Three shows combined government and private sector employment indices and employment type for 2006 and 2011, using the categories of Indigenous and NI-NS.

Source: Authors' research.

In Figure 9.5, Cluster Three data suggests that, of 160 Indigenous employees in 2006, 155 were employed in a business they did not own, but figures for owner-managers of incorporated or unincorporated enterprises are so small it is not possible to know if they are valid. In 2011, of a possible 160 Indigenous employees, 159 worked in a business they did not own and again the figures for owner-managers of incorporated or unincorporated enterprises are too low to be valid. As with Clusters One and Two, it is not possible to define the nature of those unincorporated enterprises.

The correlating findings for NI-NS status people shows 118 employees in 2006, of which six selected owner-manager of incorporated or unincorporated enterprise and the remaining 112 were employed in a business they did not own. In 2011, of a possible 68 NI-NS employees, 64 worked in a business they did not own and four worked as ownermanagers of unincorporated enterprises. The decrease in NI-NS employees occurred predominantly in private sector employment $(-70)$.

In all three clusters, non-Indigenous employment and the size of the labour force correlate. In Clusters One and Two, the non-Indigenous labour force and employment both increased while they both decreased in Cluster Three. It is argued that employment drives the size of the nonIndigenous labour force in these remote communities because virtually all non-Indigenous persons must have a job to receive accommodation or be accepted into the settlement. This employment-driven explanation is further supported by the income data shown below that indicates virtually zero unemployment among the non-Indigenous residents of the three clusters. 
For Indigenous residents, the linkage between the size of the labour force and the actual employment outcomes is not so clearly identifiable and might be more directly related to population size. In Cluster One, the Indigenous population dropped significantly, the labour force only contracted slightly, but employment went down considerably. In Cluster Two, Indigenous population went up by almost one-third, the labour market size was almost identical and Indigenous employment increased by a small amount. For Cluster Three, the population was nearly steady, the Indigenous labour force increased and the numbers of residents employed was almost the same at both time points. The data does not give a strong indication as to the drivers of Indigenous employment or unemployment, with the exception of a possible influence exerted by population size.

The information on employer type (i.e. government or private) seems unlikely to adequately describe the type and extent of mixed-market activity present in these clusters, at least in Wolf's (1993) definition of the non-market. Because the revenue for non-market activities is principally derived from taxes, donations or other non-priced sources (Wolf, 1993, p. 38), the classification of private sector employers who have tendered for and won contracts to deliver services for governments would be considered a non-market activity. However, it is unlikely that those who are working on the settlements are going to indicate they are working for government, if only because respondents to the census question may or may not know the ultimate source of the funds used to pay their wages.

Additionally, many of the employers who are operating in a more commercial environment, such as the art centres, frequently receive public grants or royalty funds to maintain their viability (Australian Government, 2015b). Again, it is unlikely that the art centre employees would indicate that they were anything other than in private employment. The large numbers of private employees in the ABS data superficially suggests the existence of a potentially significant amount of consumerdriven behaviour where the principal source of revenue comes from selling an output in an open market (Wolf, 1993, p. 39). For these remote settlements, the binary employer data is not nuanced enough to accurately understand the complexities of remote economies or their mixed markets. It is not possible to determine from the owner-manager data if any of these persons are operating in a fully commercial or entrepreneurial capacity. This distinction would assist in further distinguishing the relative contribution of markets and non-markets to determine the scale of the total mixed market. It would also inform better policy development. 
Policies supporting more market-driven behaviours by remote residents on the basis of significant 'private' employment reported in the census data are unlikely to have their intended outcomes.

\section{Income and Employment}

The next set of figures compares income and labour force data for Indigenous and NI-NS categories across clusters at the two census points. The income and labour force data in each cluster is aggregated into Indigenous, non-Indigenous or not-stated status. Income earners are classified as those actively seeking work or working at least one hour per week (ABS, 2014). Figures 9.6, 9.8 and 9.10 then aggregate income (INCP) and labour force (LFSP) data for each cluster into Non-labour force, Unemployed, Nil income or the total number of income earners $(\mathrm{A} \$ 1+)$ during the week prior to census collection. Figures 9.7,9.9 and 9.11 show brackets for income earned in the week prior to the collection point. Despite significant increases in public expenditure driven by Australian Government 'Closing the Gap' priorities (Australian Government, 2015a), the income difference between Indigenous and other employees in these remote settlements dramatically widens for income brackets above $A \$ 1,000$ per week in all three clusters. It is recognised that in 2011 the value of the dollar is less than in 2006; however, the ABS does not adjust for inflation.

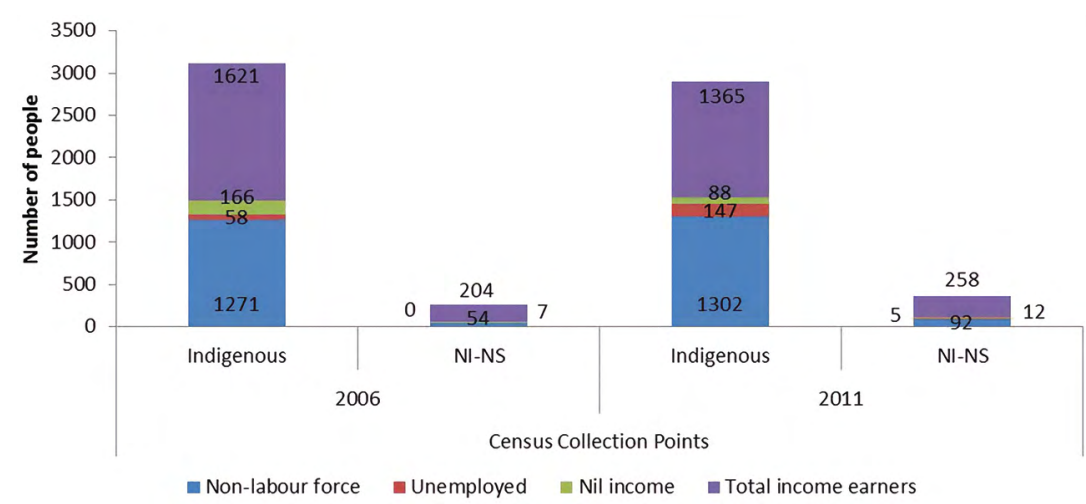

Figure 9.6: Cluster One population aggregated as non-labour force, unemployed and nil income during the week leading up to census collection, and number of income earners at any level over A\$1.

Source: Authors' research. 
Figure 9.6 shows the loss of Indigenous income earners accounted for the observed decline in population between the two collection points in Cluster One. The non-Indigenous population growth was more evenly distributed and shows very few unemployed or nil-income-earning persons, suggesting dependent partners and children contributed the NI-NS non-income increase.

Not unexpectedly, the number of income earners in Cluster One reflects the changes in population for each group. Figure 9.7 clearly demonstrates the disparity of income levels between Indigenous residents dominating the lower brackets and non-Indigenous residents occupying the bulk of the highest paid jobs in this group of settlements.

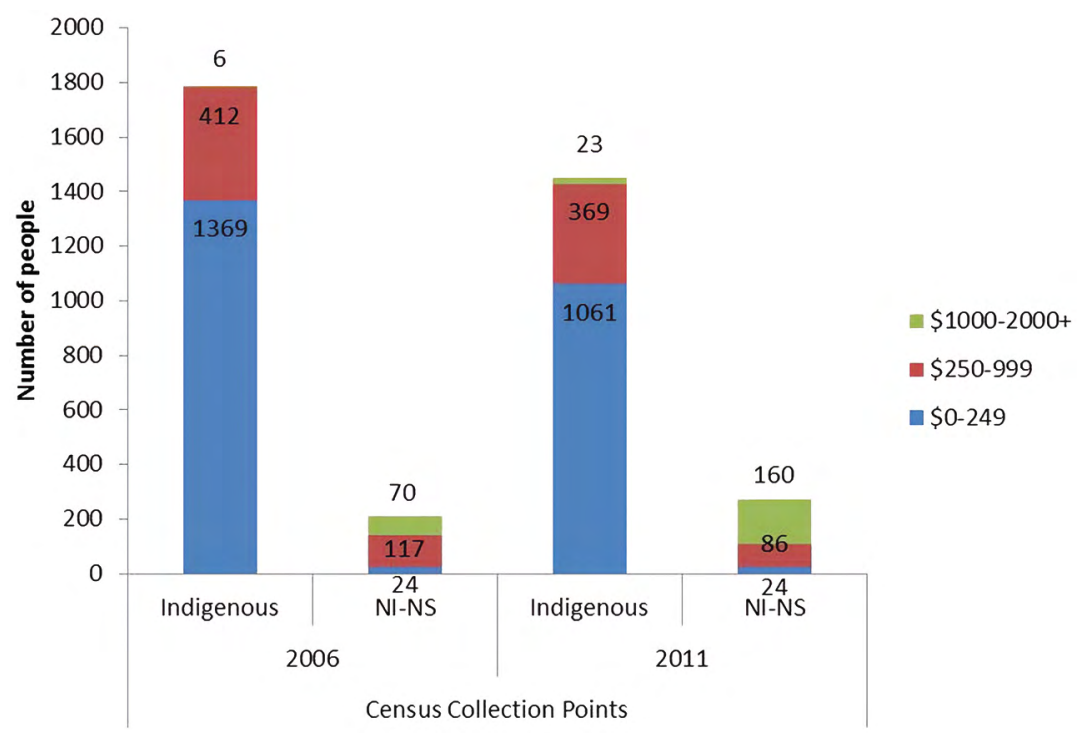

Figure 9.7: Cluster One population aggregated as non-labour force, unemployed and nil income during the week leading up to census collection, and number of income earners between $\mathbf{A} \$ 1$ and $\mathbf{A} \$ 2,000+$ per week.

Source: Authors' research.

In Cluster Two, Figure 9.8 suggests that population increase in both Indigenous and non-Indigenous residents accounts for increases in the total number income earners and the total number of non-labour force residents. The Indigenous unemployment reduced (-94), and nil income increased $(+30)$ between collection points. The only change in those categories for NI-NS residents was slight increase $(+3)$ in nil income. 


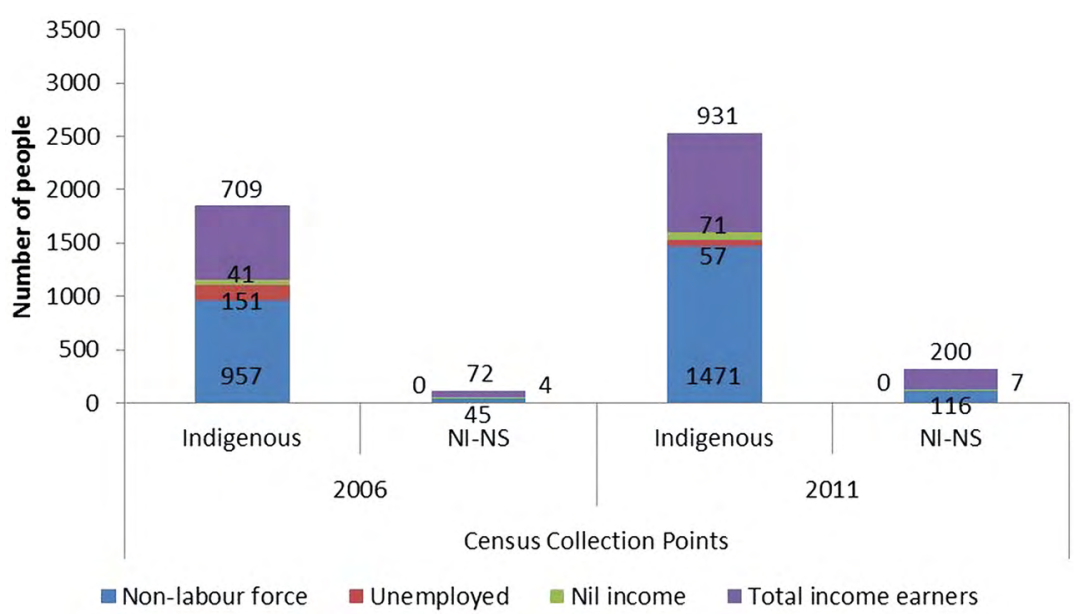

Figure 9.8: Cluster Two population aggregated as non-labour force, unemployed and nil income during the week leading up to census collection, and number of income earners at any level over $\mathbf{A} \$ 1$.

Source: Authors' research.

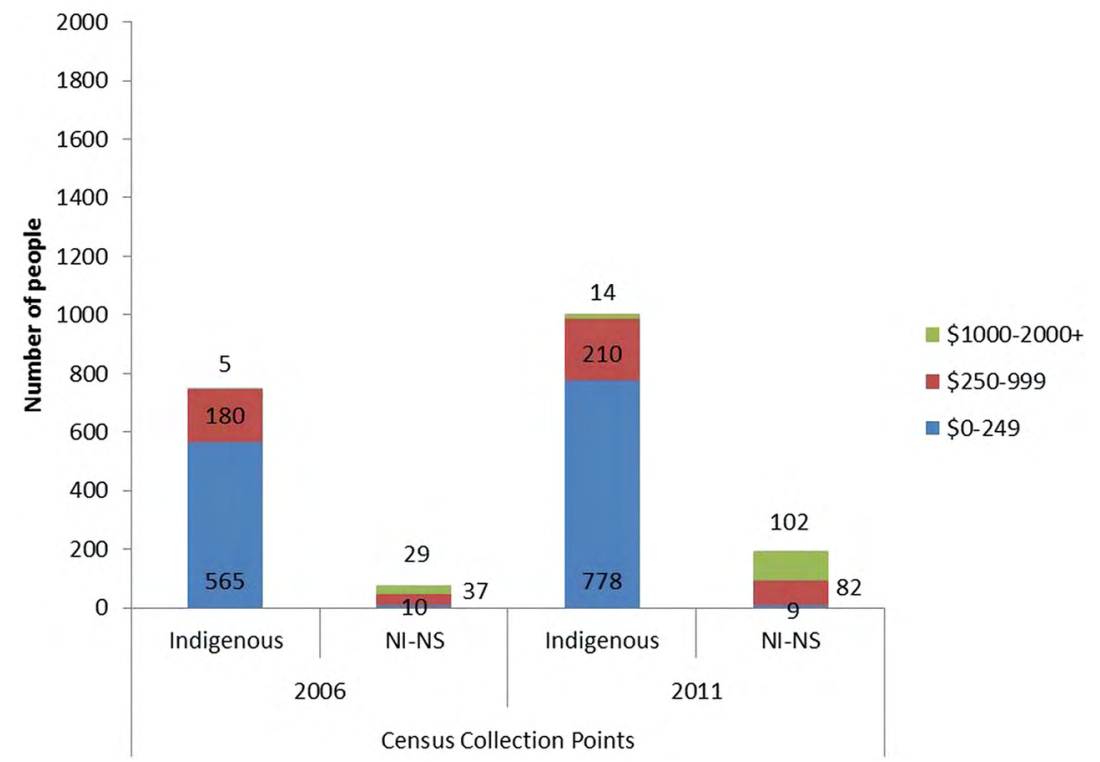

Figure 9.9: Cluster Two population aggregated as non-labour force, unemployed and nil income during the week leading up to census collection, and income earners between $\mathbf{A} \$ 1$ and $\mathbf{A} \$ 2,000+$ per week.

Source: Authors' research. 
Figure 9.9 also demonstrates that while the growth in Indigenous income earners in Cluster Two was in the lower two income bands, the higherpaid employees in these communities were from the non-Indigenous population of income earners.

In Figure 9.10, the Indigenous non-labour force and income earners remain fairly static, with a slight increase in unemployment $(+28)$ and reduction in nil income $(-43)$. The non-Indigenous or not-stated category reflects a decrease in income earners $(-46)$ and increases in all other categories $(+59)$ combined.

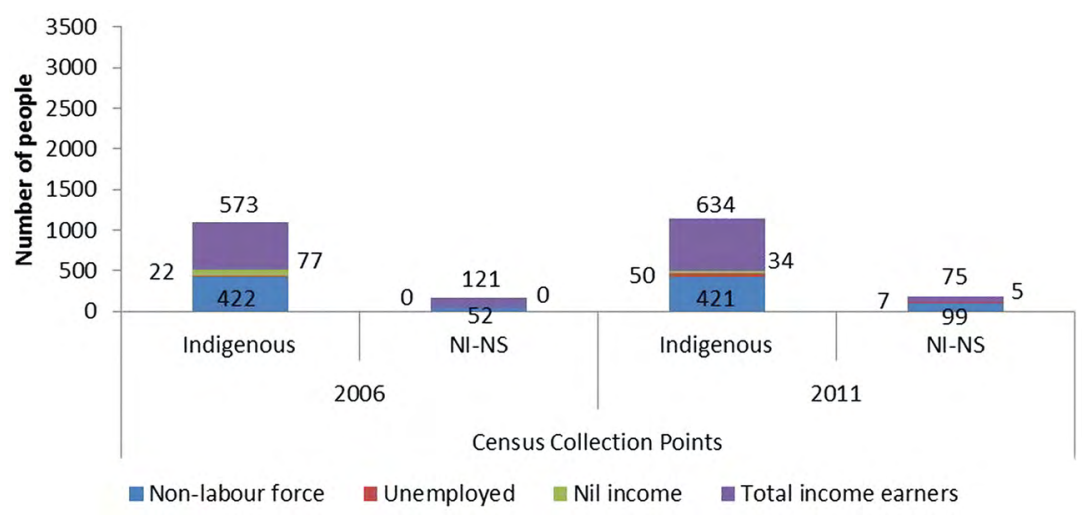

Figure 9.10: Cluster Three population aggregated as non-labour force, unemployed and nil income during the week leading up to census collection, and number of income earners at any level over $\mathbf{A} \mathbf{1 .}$

Source: Authors' research.

For Cluster Three, Figures 9.10 and 9.11 indicate relative stability in the Indigenous population at the two points in time, although none of the high-income earners from 2006 were still receiving that level of income in 2011 and the numbers of lower-income earners increased. While, yet again, non-Indigenous persons dominated the higher-income bracket in both years, the population loss was almost exclusively from the highest paid jobs in these settlements.

Industry experience shows that NI-NS higher-income earners seldom remain in any settlement for long periods of time and generally have accommodation and a motor vehicle supplied as a condition of employment. With a few minor exceptions, they spend very little of their incomes in the clusters and this disrupts any potential benefit of market- 
related circulation of money through the local economy. Policy made on the basis of total community income levels would be seriously underinformed as to the level of potential economic activity that could take place without taking into account the disaggregation demonstrated in Figures 9.6-9.11.

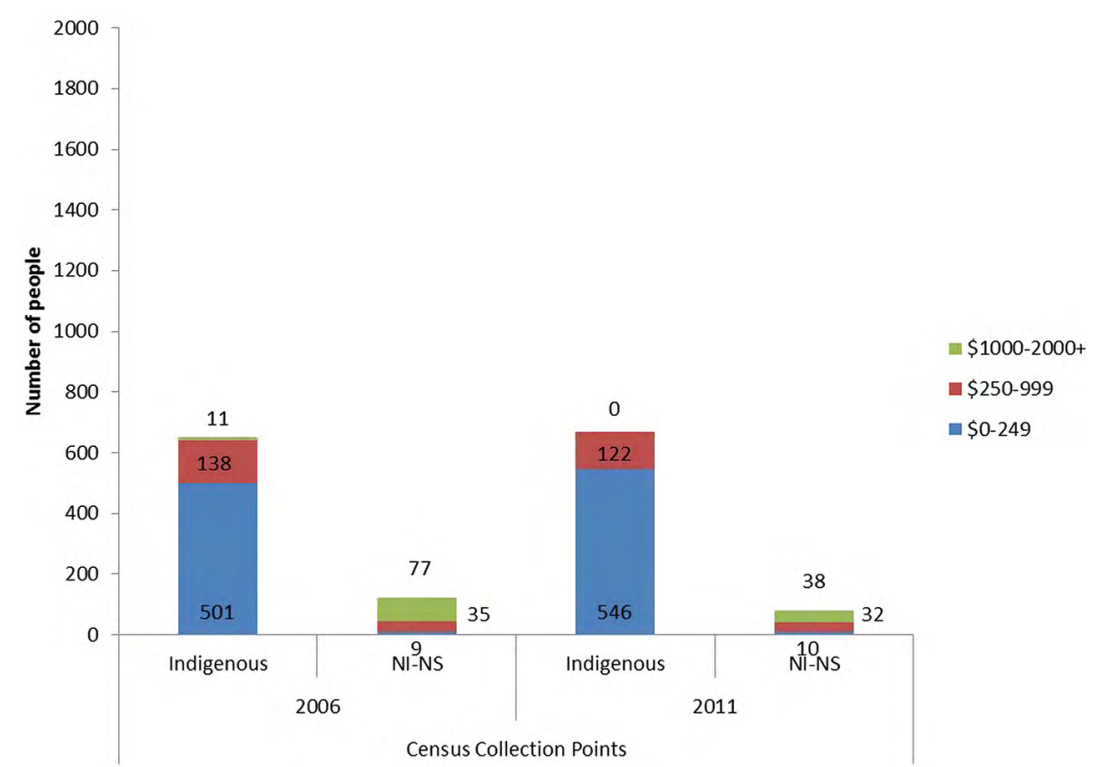

Figure 9.11: Cluster Three population aggregated as non-labour force, unemployed and nil income during the week leading up to census collection, and income earners between $\mathbf{A} \$ 1$ and $\mathbf{A} \$ 2,000+$ per week.

Source: Authors' research.

Additionally, the employer type data suggests that virtually none of these non-Indigenous high-income recipients is employed in a true market sector. The inclusion of non-Indigenous high-income earners in the SEIFA indexes skews the estimated levels of advantage upwards, as it overestimates the total of financial resources that are available in the mixed markets of these remote settlements. A variation in percentiles between settlements for the index of education and skilled employment reflects migratory staff with higher educational levels also attained higher levels of income. However, an unintended local consequence of this advantage is that the multiplier benefits of those higher incomes fall far from the remote region in which the income is derived. 
Wolf (1993) argued that non-market failure occurs where there is lack of distributional equity and it would seem that despite increased expenditure on Aboriginal policy, gains in income and employment are clearly attributed to non-local migratory residents, while local Indigenous residents of the study area have experienced an overall decline in income. The evidence suggests that the economies of these settlements are almost exclusively non-market, and income that reaches and circulates among Indigenous residents has reduced between collection points. Additionally, there was no evidence of an overall increase in Indigenous employment. These findings confirm the earlier hypothesis that, despite additional public policy and expenditure, there is no evidence of increased economic benefit to local or migratory employees or business owners derived through true market activity between the two collection points in 2006 and 2011. In addition, most recent national Indigenous employment targets for closing the gap report further decline in employment (Australian Government, 2015a, p. 5).

\section{Mixed Market and Occupation in the Clusters}

Aboriginal residents often undertake customary activity despite market or non-market ability to value or transact it (Lovell, 2015). Natural and cultural resource management, into which Indigenous ranger programs fit, is undertaken through both the mixed-market and customary structures. Aboriginal art is produced and sold opportunistically, both through and outside of Aboriginal art centres (Acker \& Woodhead, 2015). There are a number of successful research and evaluation companies who undertake casual employment of Aboriginal researchers (Limerick et al., 2014). Aboriginal community research models tend towards fee-forservice or consultancy work, delivering an output that is classified here as a market activity.

Figure 9.12 shows Indigenous occupation at their POUR for selected occupations representing arts activity, natural and cultural resource management and education at each cluster, for both census points. Education-related occupations are placed here as a non-market correlate because Aboriginal community research activity cannot be calculated due to the lack of formal figures for 2006 and the 2011 data only reflected reports from a single employer. The arts and natural and cultural resource management occupational categories represent local jobs in art centres and ranger groups but may include other places of work. 


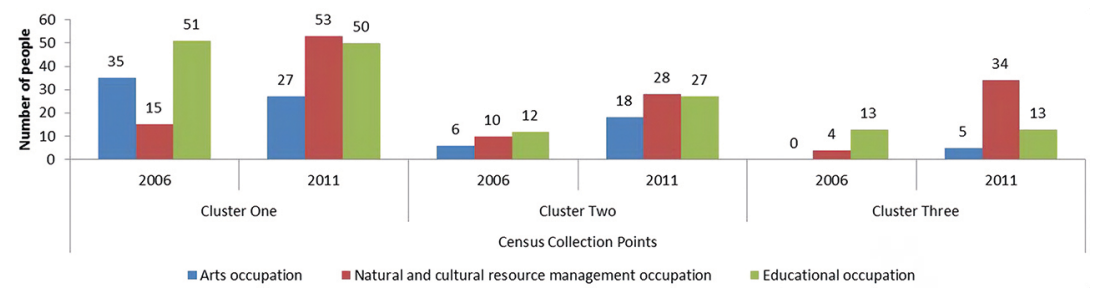

Figure 9.12: Primary occupations of Indigenous persons at place of usual residence in 2006 and 2011 census points for each settlement cluster.

Source: Authors' research.

Clusters One and Three are somewhat static in education-related occupations; however, there is a spike in Cluster Two. This suggests that there has been an increased level of employment relating to public education between 2006 and 2011 in that cluster, most likely related to the increased Indigenous population who are outside the labour force (children and parents of dependent children). The allocation of human resources to schools is directly related to student enrolment numbers and this is a likely contributor to both increases in the non-Indigenous labour force, employment and higher-level wages observed previously in this analysis. Because these settlement populations are small, natural fluctuations may contribute to the change as well. However, a spike like this might also reflect additional non-market program delivery in the cluster based on employment type data. Like other avenues of economic participation, educational initiatives come and go in remote communities and are highly dependent on (often short-term) funding cycles (Lovell et al., 2015a).

Additional federal funding (Australian Government, 2015c; Central Land Council, 2015b) for Indigenous ranger groups is reflected across all clusters by the increase in natural and cultural resource management occupations. In relation to occupational data, arts activities appear to have contracted in Cluster One, with the highest number of Aboriginal art centres and to have increased in the other clusters in spite of the total absence of formal art centres in Cluster Three. The industry navigated significant short-term program and market changes between census points as a result of welfare and employment policy shifts such as changes to Community Development Employment Programme (CDEP) and the contraction of the high-end and cosmopolitan Aboriginal arts market due to the global financial crisis in 2008 (Woodhead \& Acker, 2014). 
It can be conjectured that because the opportunistic nature of art production and sale supports a significant revenue source that derives from a market, the occupational record understates the informal economic activity. Fewer people classify art as a primary occupation since the CDEP ceased in 2008 and the arts centre-related activity changed significantly under new employment program policies (Acker \& Woodhead, 2015).

Figure 9.13 compares 2006 and 2011 census snapshots of labour force at POUR with the annual aggregate taken from financial year measures at 30 June for 2006 and 2011. The results are displayed for each cluster. All five Cluster One settlements had an active art centre in 2011 and three had active art centres in 2006. In Cluster Two, there were two active art centres in 2011 and none in 2006 while Cluster Three had no active art centres at either point. In 2011, Cluster One data from the art centres (Tim Acker, personal communication, August 2015) shows that more people still sold at least one work of art through a local art centre than were registered as part of the labour force in that cluster.

In summary, Figures 9.12 and 9.13 confirm that where mixed-market data is available it reflects the availability of local opportunity structures. Non-market contribution and a market that values residents' agency can contribute sustainable economic and social participation, as proposed by Wolf (1993, pp. 89-90) that modern economies require a balance of the two.

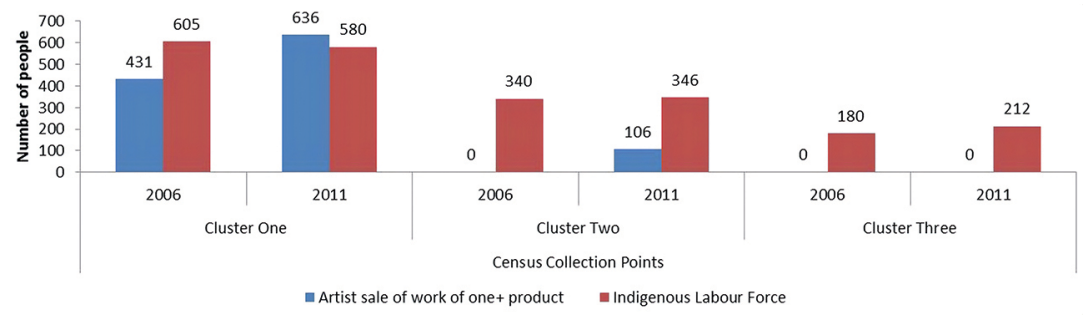

Figure 9.13: Comparison of Indigenous artists recorded as selling one or more artworks and number of Indigenous people in the labour force at place of usual residence for 2006 and 2011 census points.

Source: Authors' research. 


\section{Conclusion}

This chapter extrapolates from an earlier investigation of mixed-market activity in a sample of remote and sparsely populated Aboriginal settlements in Central Australia (Lovell et al., 2015a). That investigation found that describing some facets of mixed-market activity using national census and available industry data has provided a novel means of describing the potential for sustainable local economic participation. These findings further support the hypothesis that the concept of mixed market is a suitable lens for understanding the impact of public policy on the sustainable economic and social wellbeing of residents in remote and marginalised settlements.

In spite of their important contribution to national social and economic policy development, the two most relevant longitudinal surveys (HILDA and LSAY) are not fit for purpose when considering these mixed markets in the selected clusters of remote communities. Compared to the potential capacity of longitudinal surveys to suggest causality, the ABS census data cannot give a similar level of predictive possibility because it only captures points in time. Because SEIFA indices are constructed from ABS data, they suffer the same limitations and, unsurprisingly, correspond with the census employment and income data. The removal of Indigenous identification further reduces SEIFA's capacity to capture the mixed markets of remote NT communities.

The labour force data describes high levels of employment for nonIndigenous persons in each of the clusters and the exact opposite is true for Indigenous residents. Both groups are highly mobile, but it seems likely that while employment opportunities mobilise the non-Indigenous workforce, there are more complex factors, including population size, contributing to movements undertaken by 'locals'. The disparity in income between non-Indigenous and Indigenous residents further complicates the use of the data to determine the economy in the clusters. Averaging incomes across the entire workforce suggests higher levels of resources in the community than actually exist due to much of the non-Indigenous income never making it into the community in the first place.

The employment data, if not tempered by the application of local industry knowledge, is potentially very misleading when using the binary distinction of government or private. The large reported numbers of 'private' employees is more suggestive of suburban Canberra than remote communities and suggest the potential for more market-driven 
policymaking. This is where Wolf's (1993) more nuanced distinction between markets and non-markets, based on revenue source, becomes most illuminating. Except for a mere handful of owner-managers (most would be managers), the employees of organisations that operate in the clusters are almost exclusively in the non-market sector. On the other hand, it has been shown that both the sellers of art and artefacts and Aboriginal community researchers are operating in a market environment where their revenue is determined by a price linked to what the market will bear.

It is argued that the analysis presented here further supports the importance of mixed-market ideation to contribute to better socioeconomic policy if benefits are to be derived by local residents in remote settlements. In particular, there is evidence that in the mixed markets operating in these remote communities the market segment is dominated exclusively by individuals behaving as economically rational decision-makers. Conversely, the non-market sector is made up of organisations and their employees. Currently, these organisations and virtually all of their nonIndigenous labour force direct their economic gains away from the remote clusters in which they are derived and, therefore, reduce the financial resources available to circulate through the local economy and encourage greater market behaviour. Policy solutions that do not recognise the coexistence of individual Indigenous marketeers with those of non-market organisations seem destined to produce unintended outcomes at best and further impoverish these settlements at worst.

\section{References}

Acker, T. \& Woodhead, A. (2015). The economy of place, a place in the economy: A value chain study of the Aboriginal and Torres Strait Islander art sector. Summary report. Retrieved from www.crc-rep.com.au/resource/EconomyOf Place_WEB.pdf

Austin-Broos, D. (2011). A different inequality. Crows Nest, NSW: Allen \& Unwin.

Australian Bureau of Statistics (ABS). (2012a, 24 October). Employment type. Retrieved from www.abs.gov.au/websitedbs/censushome.nsf/home/statements personemtp?opendocument\&navpos $=430$

Australian Bureau of Statistics (ABS). (2012b, 24 September). Public/private employer indicator. Australian census. Retrieved from www.abs.gov.au/ websitedbs/censushome.nsf/home/statementspersongngp?opendocument\& navpos $=430$ 
Australian Bureau of Statistics (ABS). (2013a, 29 October). Glossary of statistical geography terminology, 2013 (Cat. No. 1217.0.55.001). Retrieved from www. abs.gov.au/ausstats/abs@.nsf/mf/1217.0.55.001

Australian Bureau of Statistics (ABS). (2013b). Census of population and housing: Socio-economic indexes for areas (SEIFA), Australia, 2011 (Cat. No. 2033.0.55.001). Retrieved from www.abs.gov.au/websitedbs/censushome. nsf/home/seifa

Australian Bureau of Statistics (ABS). (2014, 18 December). Australian demographic statistics (Cat. No. 3101.0). Retrieved from www.abs.gov.au/ausstats/abs@.nsf/ $\mathrm{mf} / 3101.0$

Australian Council for Educational Research. (1997). Longitudinal surveys of Australian youth: The Australian youth survey description. Technical paper no. 7. Melbourne: Australian Council for Educational Research.

Australian Government. (2015a). Closing the gap. Prime Minister's report. Canberra, ACT: Australian Government. Retrieved from www.pmc.gov.au/sites/default/ files/publications/Closing_the_Gap_2015_Report.pdf

Australian Government. (2015b). Indigenous Languages and arts program. Retrieved from arts.gov.au/topics/indigenous-arts-languages-and-culture/ indigenous-languages-and-arts

Australian Government. (2015c, 6 February). Indigenous Ranger Programs. Retrieved from www.niaa.gov.au/indigenous-affairs/environment/indigenousranger-program

Carson, D. \& Carson, D. (2014). Local economies of mobility in sparsely populated areas: Cases from Australia's spine. Journal of Rural Studies, 36, 340-349.

Carson, D., Ensign, P. C., Rasmussen, R. \& Taylor, A. (2015). Perspectives on 'Demography at the Edge'. In D. Carson, R. Rasmussen, L. Huskey, P. C. Ensign \& A. Taylor (Eds), Demography at the edge. Human populations in developed nations (pp. 3-20). Farnham, England: Ashgate.

Central Land Council. (2015a). CLC homepage facts. Retrieved from www.clc. org.au/

Central Land Council. (2015b). Ranger program development strategy. Retrieved from www.clc.org.au/publications/content/ranger-program-development-report

Department of the Prime Minister and Cabinet. (2014). Indigenous advancement strategy guidelines. Canberra: Australian Government. 
Dockery, A. (2014a). Reconceptualising mobility for Aboriginal and Torres Strait Islander Australians. Retrieved from www.crc-rep.com.au/resource/CW015_ ReconceptualisingMobility.pdf

Dockery, A. (2014b). A wellbeing approach to mobility and its application to Aboriginal and Torres Strait Islander Australians. Social Indicators Research, 125(1), 243-255.

Forrest, A. (2014). Creating party - The Forrest review. Canberra: Commonwealth of Australia. Retrieved from www.niaa.gov.au/resource-centre/indigenousaffairs/forrest-review

Haslam McKenzie, F. (2011). Attracting and retaining skilled and professional staff in remote locations of Australia. The Rangeland Journal, 33(4), 353-363.

Jones, R. (2002). Longitudinal surveys of Australian youth: Education participation and outcomes by geographic location (Research Report No. 26). Retrieved from www.lsay.edu.au/publications/1865.html

Limerick, M. C., Department of the Prime Minister and Cabinet, Brunton, C., O’Brien Rich Research Group \& Putt, J. C. (2014). National partnership agreement on remote Service delivery evaluation 2013. Canberra, ACT: Australian Government. Retrieved from www.niaa.gov.au/sites/default/files/ publications/npa-remote-service-delivery-evaluation-2013.PDF

Lovell, J. (2015). Customary assets and contemporary artistry: Multimodal learning and remote economic participation. The Australian Journal of Indigenous Education, 44(2), pp. 184-193. doi.org/10.1017/jie.2015.24

Lovell, J., Guenther, J. \& Zoellner, D. (2015a, 20-22 July). Developing Northern Australia: Recognising remote mixed-market economies. Paper presented at the Developing Northern Australia: Economically, Socially, Sustainably conference, Townsville, Queensland.

Lovell, J., Guenther, J. \& Zoellner, D. (2015b). Northern Australian aspirations. Retrieved from www.cdu.edu.au/sites/default/files/research-brief-2015-07 -0.pdf

Lovell, J., Zoellner, D., Guenther, J., Brouard, F. \& McMurtry, J. (2016). Contemporary Aboriginal settlements: Understanding mixed-market approaches. In A. Taylor, D. Carson, P. Ensign, L. Huskey \& R. Rasmussen (Eds), Settlements at the edge: Remote human settlements in developed nations (pp. 246-269). Oxon, England: Ashgate.

Morrison, J. (2015). Northern Development: Embracing the Indigenous difference [Press release]. Darwin: Northern Land Council. 
Nakata, M. (2007). The cultural interface. The Australian Journal of Indigenous Education, 36(5), 2-14.

National Centre for Vocational Education Research. (2014). Longitudinal surveys of Australian youth: Annual report 2013 Retrieved from www.lsay.edu.au/ publications/2761.html

Pearson, C. \& Daff, S. (2014). Female Indigenous entrepreneurship in remote communities in Northern Australia. Information Management and Business Review, 6(6), 329-344.

Sengupta, U., Vieta, M. \& McMurtry, J. (2015). Indigenous communities and social enterprises in Canada. ANSERJ: Canadian Journal of Nonprofit and Social Economy Research/Revue canadienne de recherche sur les OSBL et l'économie sociale, 6(1), 103-123.

Steering Committee for the Review of Government Service Provision. (2014). Overcoming Indigenous disadvantage: Key indicators 2014. Retrieved from www.pc.gov.au/research/recurring/overcoming-indigenous-disadvantage/keyindicators-2014/key-indicators-2014-report.pdf

Taylor, A., Payer, H. \& Brokensha, H. (2015). The demography of developing Northern Australia. Retrieved from www.cdu.edu.au/sites/default/files/researchbrief-2015-06.pdf

Watson, N. \& Wooden, M. (2002). The Household, Income and Labour Dynamics in Australia (HILDA) survey: Wave 1 survey methodology (HILDA Project Technical Paper Series No. 1/02 [Revised October 2002]). Retrieved from melbourneinstitute.unimelb.edu.au/assets/documents/hilda-bibliography/ hilda-technical-papers/htec102.pdf

Wilkins, Roger. (2015). The Household, Income and Labour Dynamics in Australia survey: Selected findings from waves 1 to 12. Melbourne: Melbourne Institute of Applied Economic and Social Research, University of Melbourne.

Woinsarski, J., Traill, B. \& Booth, C. (2014). The modern outback. Nature, people and the future of remote Australia. Retrieved from www.pewtrusts.org/en/ research-and-analysis/reports/2014/10/the-modern-outback

Wolf, C. (1993). Markets or governments: Choosing between imperfect alternatives (2nd ed.). Cambridge, MA: MIT Press. Retrieved from www.rand.org/pubs/ notes/N2505.html

Woodhead, A. \& Acker, T. (2014). The art economies value chain reports: Synthesis. Retrieved from www.crc-rep.com.au/resource/CR004_AEVC_Synthesis.pdf 
This text is taken from Leading from the North: Rethinking Northern Australia Development, edited by Ruth Wallace, Sharon Harwood, Rolf Gerritsen, Bruce Prideaux, Tom Brewer, Linda Rosenman and Allan Dale, published 2021 by ANU Press, The Australian National University, Canberra, Australia.

doi.org/10.22459/LN.2021.09 